\title{
07 PARTNERING TO PREVENT FIRE INJURY AT THE COMMUNITY LEVEL: TRIUMPHS AND CHALLENGES FROM THE FRONT LINES
}

doi:10.1136/injuryprev-2012-040590c.7

S Frattaroli, E McDonald, V Jones, W Shields, A Gielen. The Johns Hopkins

Bloomberg School of Public Health, Center for Injury Research and Policy, USA

Background Community-based interventions are a recognised approach to fire prevention because such an approach aims to achieve population level changes and is not limited to high-risk groups or individuals. Community-based work involves partnerships, often with multiple partners-yet the literature offers little guidance about how to develop and maintain effective partnerships.

Aims/Objectives/Purpose To describe individuals' experiences as part of a diverse research-practice partnership that was active over several years and oversaw a community trial of a home visit smoke alarm distribution programme. To identify lessons to inform future partnered research.

Methods We conducted a series of semistructured key informant interviews with partners in the Johns Hopkins Home Safety Study (JHHSS).

Results/Outcomes Between July 2011 and January 2012 we conducted 12 interviews with the JHHSS partners. We were unable to interview one individual who changed jobs at the end of the project. Interviewees attributed the importance of fire and concordance between the partnership's mission and their own organisational priorities as central to their participation. They also cited the strong administrative arm of the partnership as a factor in their continued participation, but emphasised that same infrastructure could have been more proactive in disseminating information among the partnership and engaging the community. Interviewees cited high staff turnover and selection of communities based on statistical, rather than neighbourhood criteria as reasons for some of these challenges.

Significance/Contribution to the Field Understanding how to develop and maintain diverse partnerships is a key component of effective community-based intervention work. 